\title{
A Comparison of Functional and Physical Properties of Self-Expanding Intracranial Stents [Neuroform3, Wingspan, Solitaire, Leo(+), Enterprise]
}

\author{
Authors \\ Ö. Krischek ${ }^{1}$, E. Miloslavski ${ }^{1}$, S. Fischer ${ }^{1}$, S. Shrivastava ${ }^{2}$, H. Henkes ${ }^{1}$ \\ Affiliations \\ ${ }^{1}$ Klinik für Neuroradiologie, Klinikum Stuttgart, Stuttgart, Germany \\ ${ }^{2}$ Covidien/ev3, Irvine, CA, USA
}

\section{Key words \\ - stents \\ - Neuroform \\ - Wingspan \\ - Solitaire \\ - Leo+ \\ - Enterprise}

Bibliography

DOI http://dx.doi.org/

10.1055/s-0031-1271681

Minim Invas Neurosurg 2011;

54: 21-28

(c) Georg Thieme Verlag KG

Stuttgart · New York

ISSN 0946-7211

\section{Correspondence}

Prof. Dr. med. H. Henkes

Klinik für Neuroradiologie

Klinikum Stuttgart

Kriegsbergstraße 60

70174 Stuttgart

Germany

Tel.: + 49/711/278 34501

Fax: $+49 / 711 / 27834509$

HHHenkes@aol.com

\section{Abstract}

$\nabla$

Purpose: 5 self-expanding intracranial stents Neuroform (N), Wingspan (W), Solitaire (S), Leo $(+)(\mathrm{L})$, and Enterprise (E) were subjected to an in vitro examination and comparison of their physical features and functional properties in order to better understand the clinical advantages and potential limitations of each device.

Material and Methods: The following features were examined for each stent: visual appearance, radial strength, wall apposition, bending stiffness, gator backing, kink resistance, ovalization, vessel wall coverage, cell size, ease of delivery.

Results: Given are rankings for the 5 stents: radial force at $50 \%$ oversizing: $\mathrm{L}<\mathrm{N}<\mathrm{E}<\mathrm{S}<\mathrm{W}$; radial

\section{Introduction}

\section{$\nabla$}

A wide aneurysm neck (i.e., $4 \mathrm{~mm}$ or more) turned out to be the major limitation for the endovascular coil treatment of intracranial aneurysms [1]. The creation of an artificial border between the parent artery and the aneurysm orifice by deployment of a balloon-expandable coronary stent was the initial solution [2]. However, the insufficient flexibility of balloon-mounted stents and the risk of parent vessel and/or aneurysm injury prevented the general acceptance of the method. The Cerebrence (Medtronic) is a balloon-mounted coronary stent derivative, approved for the treatment of intracranial aneurysms in the EU, but which was finally withdrawn from the market [3]. In 2001, the Neuroform (Smart Therapeutics, acquired by Boston Scientific) was the first self-expanding microstent to be developed and approved to assist the coil occlusion of wide-necked intracranial aneurysms [4]. In 2008, a modification of this stent was launched as Wingspan (Boston Scientific) with an improved delivery system and an increased force at $15 \%$ oversizing $\mathrm{L}<\mathrm{E}<\mathrm{S}<\mathrm{N}<\mathrm{W}$; wall apposition: $\mathrm{E}<\mathrm{N}=\mathrm{W}<\mathrm{S}$; bending stiffness: $\mathrm{N}<\mathrm{L}<\mathrm{W}<\mathrm{S}<\mathrm{E}$; gatorbacking: NandWonly; kink resistance: $\mathrm{N}=\mathrm{W}<$ $\mathrm{E}<\mathrm{S}<\mathrm{L}$; ovalization: $\mathrm{W}<\mathrm{L}<\mathrm{S}<\mathrm{N}<\mathrm{E}$; vessel wall coverage: $\mathrm{S}<\mathrm{E}<\mathrm{N}<\mathrm{W}<\mathrm{L}$; cell size: $\mathrm{L}<\mathrm{W}<\mathrm{E}<\mathrm{N}<\mathrm{S}$; ease of delivery: $\mathrm{W}<\mathrm{N}<\mathrm{L}<\mathrm{E}<\mathrm{S}$. A comparative analysis of the in vitro test results with the clinical experience of the authors is presented in this paper.

Conclusion: The 5 stents have fundamentally different features and there is no stent that is superior in all tested aspects. The selection in an individual treatment should be based on clinical and technical requirements.

radial force for the endovascular treatment of intracranial atherosclerotic stenoses [5]. Both stents have an open cell design and are neither resheathable nor correctable once the first stent element has been deployed. The Solitaire (Dendron, acquired by ev3, Inc.) as the first closed-cell design, self-expanding stent for intracranial vessels received its initial CE mark in $2003[6,7]$. This stent can be either retrieved or electrolytically detached after full deployment. The Enterprise (Codman Neurovascular) is another self-expanding closed-cell design microstent. This stent can be retrieved into the delivery catheter unless more than two thirds of the entire stent length has been deployed [8,9]. All these stents are laser-cut from Nitinol hypotubes. The Leo and Leo +, in contrast, are braided structures made from a single Nitinol wire [10]. This stent can be retrieved into the delivery catheter unless more than $90 \%$ of the entire stent length has been deployed. During the last decade, these devices became widely used and generally accepted for the endovascular treatment of intracranial aneurysms. The approved use for 
intracranial atherosclerotic stenoses is currently limited to Wingspan. Thrombectomy for acute ischemic stroke with Solitaire was anticipated early in the product history and is proving to be very effective [6].

The physical features, the dimensions, and the functional characteristics of these implants show major differences. We assume that physicians follow personal preferences and are guided by their clinical experience in the decision-making for which stent they will use in an individual case. Although some aspects of stent design have been reported in the literature, many stent features and their effect on functional properties are not well understood. We sought to determine and compare the most relevant properties of the currently available intracranial selfexpanding stents. Knowledge of these features may help physicians in selecting the most appropriate stent for a given vascular anatomy and clinical purpose and enable them to anticipate its behavior and potential issues. Despite the affiliation of one senior author to ev3 (SS), we tried our best to be as neutral and balanced in the description and interpretation of our observations as possible. We do not feel that any of the examined stents is "the best" but rather think that for a given anatomy or purpose, one stent may be better suited than others.

\section{Material and Methods}

$\nabla$

The intracranial aneurysm neck bridging stents Neuroform3 (Boston Scientific), Solitaire (ev3), Leo + (Balt) and Enterprise (Codman Neurovascular) and in addition the stenosis-stent Wingspan (Boston Scientific) were analyzed for various functional and structural attributes. For this purpose, 1-10 units of each stent were used with varying frequencies, as listed in each test.

For visual comparison, images with identical magnification factors $(10 \times$ and $40 \times)$ were taken. Official indications and available dimensions were listed.

The radial force (often termed as "outward radial force" or "radial strength") of a stent corresponds to the force that the stents exerts on the vessel wall and that is available to support the coils inside an aneurysm. There are several methods to measure the radial force of stents. They include the "Iris Test", the "V-Block Test", the "Flat Plate Test", the "Thin Film Test" and the "Pressure Chamber Test". We collected data using the "Flat Plate Test", which is the most commonly used method and allows us to measure radial force of all stents regardless of their design. The "Flat Plate Test" places the stent between 2 flat plates and the radial force of the stent is measured during compression of the 2 plates. In this study, radial force data were collected while the stent diameter was being expanded at $50 \%$ of the labeled diameter of the stent, which corresponds to what is sometimes termed as the chronic outward force [11]. We also collected data using the "Thin Film Test", which can compress the stent circumferentially through 360 degrees and can measure changes in diameter vs. force for both expansion and contraction. In this study, radial force data were collected for chronic outward force. When a stent is delivered to the target site through the microcatheter and deployed, the device will self-expand to a larger diameter by the elastic energy stored in the stent structure until equilibrium is reached between the stored elastic energy and the opposing force from the surrounding vessel. The stored elastic energy in the stent structure produces an outward force known as chronic outward force against the vessel wall. The chronic outward force (also termed as outward radial force) data were collected while expanding the vessel diameter at about $85 \%$ of the labeled vessel diameter.

The wall apposition describes a stent's ability to remain in close contact with the adjacent vessel wall when deployed in a curved vessel. Stents were deployed in $3 \mathrm{~mm}$ tubes having a $3.9 \mathrm{~mm}$ centerline radius and in $4 \mathrm{~mm}$ tubes with a $4.4 \mathrm{~mm}$ centerline radius. Images were captured to visually observe the apposition of each stent with the vessel wall in the curved segment.

Conformability describes a stent's ability to adopt the tortuous path of a vessel, instead of forcing the vessel to straighten. In this study, it was measured by quantifying bending stiffness. Bending stiffness for each stent was determined by measuring the force exerted by a stent when bent around a $12.5 \mathrm{~mm}$ block using mechanical testing equipment manufactured by MTS Systems Corporation. That force was multiplied by the length to obtain the bending moment.

Gator backing describes a stent's tendency to flair its struts outward, forming protrusions, when the stent is placed around a bend. The appearance of gator-backing resembles the scales on the back of an alligator. Excessive gator backing may result in poor prevention of coil herniation. To visualize gator backing, stents were deployed within a $3 \mathrm{~mm}$ silicone tube with a $12.5 \mathrm{~mm}$ radius curve and visually evaluated for the extend of gator backing across the "aneurysm neck".

Kinking is the buckling of a stent when it is bent over a curve. Kinking can result in vessel occlusion. It was measured by deploying stents within $3 \mathrm{~mm}$ silicone tubes with a $12.5 \mathrm{~mm}$ radius curve and visually evaluate the extent of kinking.

Ovalization describes the phenomenon of the stent lumen flattening when it is curved ( $\bullet$ Fig. 1). This may result in flattening of the vessel lumen and ultimately vessel occlusion. Ovalization was tested by deploying the stent into a thin-walled silicone tube and bending the vessel into a $10 \mathrm{~mm}$ radius arc. Measured were the minor and major axis lengths of the stent's cross-section. Calculated was the eccentricity to quantify ovalization:

The ability of a neck bridging stent to hold coils inside an aneurysm and the interaction between stent and parent vessel can be measured as the vessel wall coverage. Vessel wall coverage was calculated by deploying stents in mock vessels of indicated diameters and measuring the uncovered surface area using a microscope and software program.

The cell size finally determines the difficulty or ease to catheterize an aneurysm once its orifice is bridged by a stent. The stability of coil retention in an aneurysm is also a function of cell size. Cell sizes of the compared stents were measured under the microscope.

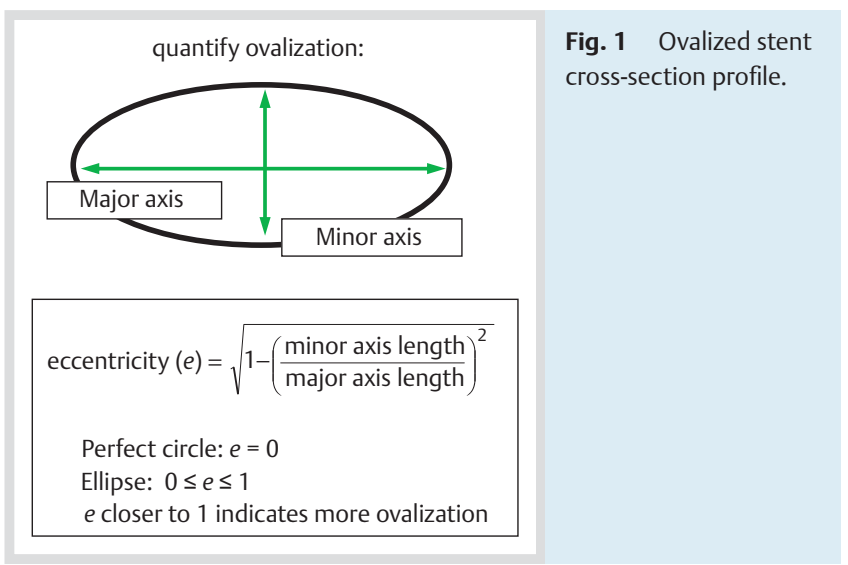


The method of delivery determines the required effort to deploy a stent into the target vessel. The various delivery methods were analyzed from the perspective of clinical functionality.

\section{Results}

Magnified views of the structures of the 4 stents further examined may help to understand their features and are shown in $\boldsymbol{0}$ Fig. $\mathbf{2}$. Indications and available sizes are listed in $\bullet$ Table 1.

- Fig. 3 shows a comparison of the radial force as measured by the "Flat Plate Test", of the 4 aneurysm stents and in addition of the Wingspan stent. Given is the radial force at $50 \%$ compression in the "Flat Plate Test", with average, maximum and minimum values displayed. There is a clear rank starting with Leo + as the stent with the lowest radial strength, followed by Neuroform3, Enterprise, Solitaire and Wingspan. It may be emphasized that the Wingspan stent has about the 3-fold radial strength of the Leo+ stent. 5 measurements were conducted on each stent and varying sample sizes were used for each stent $(\mathrm{Leo}+=2$, Enterprise $=4$, Neuroform $=3$, Wingspan $=2$, Solitaire $=10$ ).

- Fig. 4 shows a comparison of the chronic outward force (outward radial force), as measured by the "Thin Film Test", of the 4 aneurysm stents and in addition of the Wingspan stent. There is a clear rank starting with Leo+ as the stent with the lowest radial force followed by Enterprise, Solitaire, Neuroform 3 and Wingspan. One measurement per stent was conducted using 5 test cycles for each stent $($ Leo $+=1$, Enterprise $=1$, Neuroform $3=2$, Wingspan $=2$, Solitaire $=30$ ). It is clear that Leo + has the lowest radial force and Wingspan has the highest radial force among all stents tested independent of the test method. Relative ranks of Neuroform 3 and Solitaire changes are based on the test method. At higher oversizing, Solitaire shows higher radial force and at lower oversizing Neuroform 3 shows higher radial force. This is attributed to their specific design features. At lower oversizing, an unrolling mechanism may be operative in Solitaire due to a longitudinal split in its design thereby showing lower radial force. Additionally, the closed cell designs tend to exhibit a higher radial force at higher oversizing.

The wall apposition was evaluated in $3 \mathrm{~mm}$ tubes having a $3.9 \mathrm{~mm}$ radius (O Fig. $\mathbf{5 a}$ ) and in $4 \mathrm{~mm}$ tubes with a $4.4 \mathrm{~mm}$ radius ( $\bullet$ Fig. $\mathbf{5 b}$ ). Neuroform3, due to the open cell design, maintains good wall apposition even in tortuous paths. The wall apposition of the Solitaire stent is similar to that of the Neuroform but better than that of the Enterprise. The wall apposition

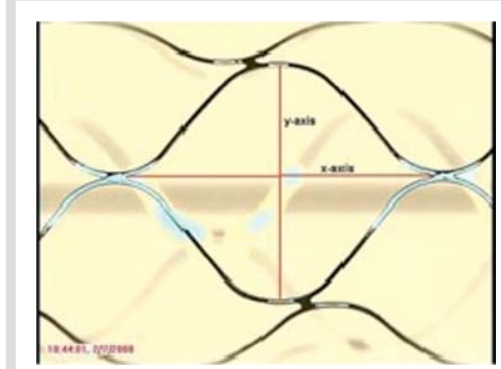

Solitaire - closed

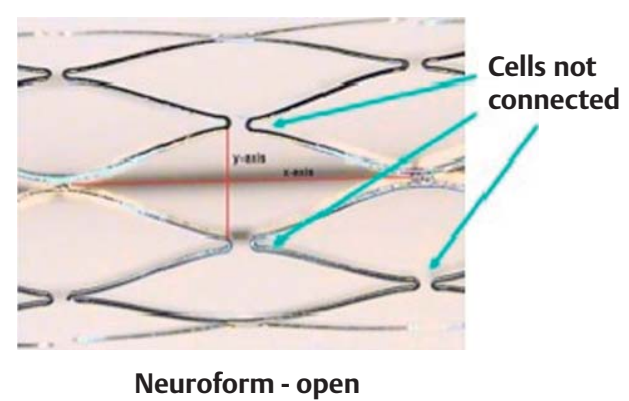

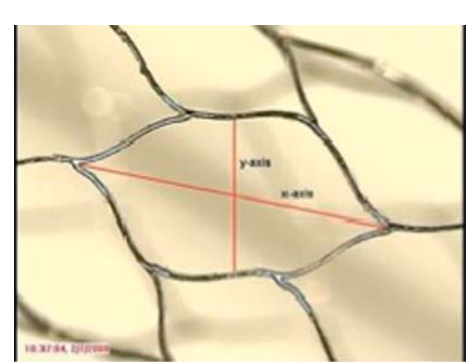

Enterprise - closed

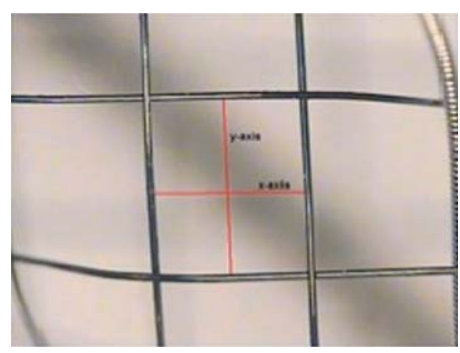

Leo Plus - closed
Fig. 2 Cell patterns of Solitaire, Neuroform3, Enterprise, and Leo + are shown. The Wingspan stent has a similar cell pattern as the Neuroform3.

Table 1 Summary of the characteristics of various commercially available stents.

\begin{tabular}{|c|c|c|c|c|c|}
\hline & Solitaire (ev3) & Enterprise (Codman) & Neuroform (Stryker) & Wingspan (Stryker) & Leo Plus (Balt) \\
\hline indication & $\begin{array}{l}\text { intracranial vascular } \\
\text { disease }\end{array}$ & intracranial aneurysms & intracranial aneurysms & $\begin{array}{l}\text { intracranial atheroscle- } \\
\text { rotic stenosis }\end{array}$ & $\begin{array}{l}\text { intracranial } \\
\text { aneurysms }\end{array}$ \\
\hline $\begin{array}{l}\text { retrievable/ } \\
\text { repositionable }\end{array}$ & yes & partially & no & no & partially \\
\hline sizes: diameter (mm) & $3,4,5,6$ & 4.5 & $2.5,3,3.5,4,4.5$ & $2.5,3,3.5,4,4.5$ & $2.5,3.5,4.5,5.5$ \\
\hline lengths (mm) & $15,20,30,40$ & $14,22,28,37$ & $10,15,20,30$ & $10,15,20$ & $\begin{array}{l}12,15,18,20,25 \\
30,35,40,50,75\end{array}$ \\
\hline vessel range $(\mathrm{mm})$ & $2.25-5.5$ & $2.5-4$ & $2-4.5$ & $2-4.5$ & $2-5.5$ \\
\hline cell type & closed & closed & open & open & closed \\
\hline $\begin{array}{l}\text { radial force ( } 1-4 \text {, where } 4 \\
\text { is the highest) }\end{array}$ & 2 & 2 & 3 & 4 & 1 \\
\hline markers & $\begin{array}{l}3 \text { distal and } 1 \\
\text { proximal }\end{array}$ & 4 markers on each end & 4 markers on each end & 4 markers on each end & $\begin{array}{l}2 \text { platinum threads } \\
\text { on stent body }\end{array}$ \\
\hline
\end{tabular}




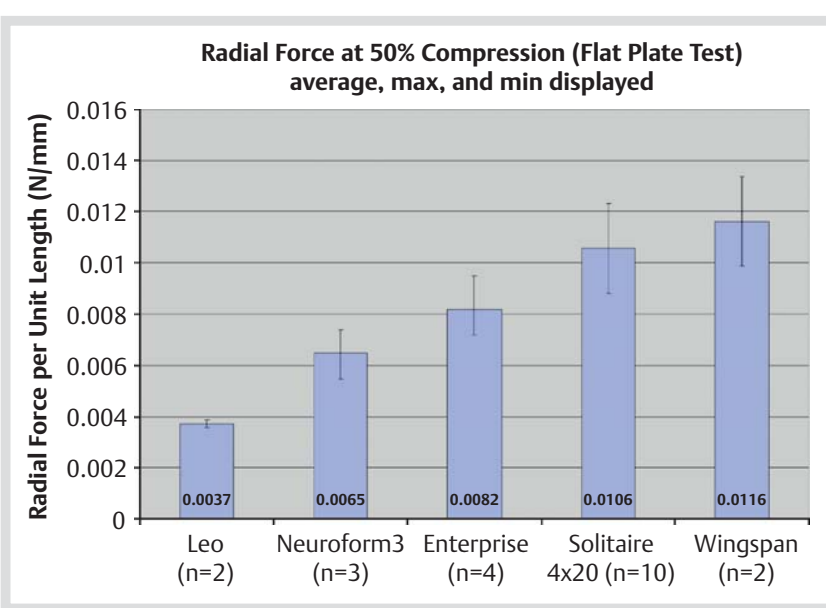

Fig. 3 Comparison of the stents' radial force at $50 \%$ compression using a "Flat Plate Test".

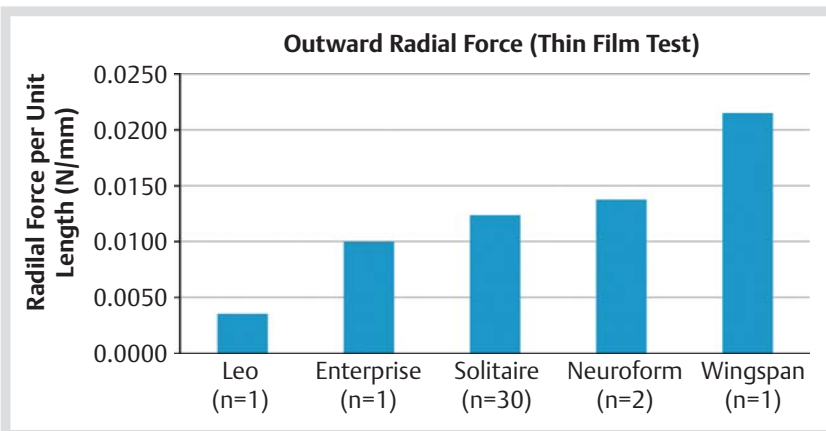

Fig. 4 Comparison of the stents' chronic outward force using a "Thin Film Test".

of the Leo+ stent is highly dependent on the technique of deployment. We therefore omitted this evaluation.

The bending stiffness was determined as the moment required for bending a given stent into a 0.5 inch $\operatorname{arc}(\triangleq 12.7 \mathrm{~mm})$. One measurement was taken for each stent $($ Leo $=2$, Enterprise $=3$, Neuroform $3=2$, Wingspan $=2$, Solitaire $=3$ ). Results are shown in $\odot$ Fig. 6. Enterprise has the highest bending stiffness (100\%), followed by Solitaire (55\%), Wingspan (44\%), Leo + (36\%), Neuroform3 (30\%). The vessel straightening is expected to be the highest for the Enterprise stent.

The results of gator backing visualization are presented in $\odot$ Fig. 7. Only Neuroform3 (and Wingspan) displayed gatorbacking. It was not observed with the other stents.

Kinking was tested in $3 \mathrm{~mm}$ silicone tubes with a $12.5 \mathrm{~mm}$ radius curve. Results are shown in 0 Fig. 8. One measurement was taken for each stent (Leo $+=2$, Enterprise $=4$, Neuroform $3=1$, Wingspan $=1$, Solitaire $=1$ ). The Solitaire and Leo + did not kink around a 1-inch curve. Both, Neuroform 3 and Wingspan kinked under these conditions. Enterprise kinked less than Neuroform. The results of testing for ovalization are summarized in - Fig. 9a, b. In the stent ovalization in $3 \mathrm{~mm}$ and $4 \mathrm{~mm}$ curved vessels, each stent was measured 3 times (Leo $+=2$, Enterprise $=4$, Neuroform $3=2$, Wingspan $=1$, Solitaire $=1)$. Of the laser cut stents, Enterprise ovalizes the most, while the Wingspan ovalizes the least. Solitaire ovalizes less than Neuroform 3 and Enterprise. Leo + undergoes ovalization, but the extent of ovalization cannot be compared to the other competitor stents. Leo+ does not maintain wall apposition when it is bent. Its kink resist- ance, conformability, and ovalization are also highly dependent on the deployment technique. The characteristics presented here pertain to the ideal deployment of a Leo+ stent.

The vessel wall coverage varies in a wide range between the tested stents. 0 Fig. 10a, b show the results for $3 \mathrm{~mm}$ and $4 \mathrm{~mm}$ vessels. Solitaire has the lowest vessel wall coverage of all studied intracranial stents. However, this stent has an overlap design, where the aneurysm neck may to be covered by the overlap area. Only when vessel wall coverage is determined for the overlap areas, does it have twice the coverage and which is close to that of Enterprise and Neuroform3. Enterprise and Neuroform3 have similar percentages of vessel wall coverage. A lower percentage of vessel wall coverage may reduce the risk of adverse effect of the stent on the vessel wall. More vessel wall coverage is certainly a requirement for a significant hemodynamic effect. One measurement was taken for each stent $($ Leo $+=1$, Enterprise $=1$, Neuroform $3=1$, Wingspan $=1$, Solitaire $=1$ ).

The cell size was measured. 5 cells were measured on each stent $($ Leo $+=3$, Enterprise $=4$, Neuroform $3=1$, Wingspan $=1$, Solitaire $=1$ ). The ranking starts with Solitaire as the stent with the largest cell size, followed by Neuroform3, Enterprise, Wingspan and Leo+.

The methods of delivery of the 5 stents differ significantly. The Neuroform 3 stent comes premounted in a 0.027 " ID outer microcatheter (Renegade hi flo) and the stent is pushed out of the catheter with an inner catheter, called a stabilizer. Both preparation and insertion of the catheter/stabilizer ensemble are slightly cumbersome and may require assistance from a second person. This drawback is overcome with the latest version of the Neuroform stent ("Neuroform EZ"). Wingspan is also premounted, but the deployment results from the retrieval of an outer catheter, similar to the mechanism of the Wallstent. Leo+, Enterprise and Solitaire are not premounted and are delivered through separate microcatheters. The Leo+ stents are only deployable through dedicated Vasco catheters.

\section{Discussion}

This work should be a first step towards a comprehensive "physician's guide" for intracranial stents, as they are available for coronary [12] and carotid stents [13].

The features of the 5 intracranial stents examined in this study are very different. Some of the above-described observations correspond well with other in vitro studies and with clinical experience. The assessment of each stent has to consider various aspects. How well does a stent meet the primary requirements (i.e., retain coils in a wide necked aneurysm)? What effects have to be expected in this context (e.g., vessel straightening, difficulty in catheterizing an aneurysm through stent struts)? How about secondary effects such as hemodynamic influence on the aneurysm? Can adverse effects (e.g., intimal hyperplasia with in-stent stenosis) be expected or anticipated from certain stent features?

The Neuroform was the first self-expanding intracranial stent and became available in a clinical trial in Europe in 2001 [4]. Since then, a large number of publications have focused on various aspects of this device. The basic structure of the Neuroform is a sequence of sinusoidal crown segments of $2.5 \mathrm{~mm}$ length. Adjacent crowns have 2 or 3 connecting points. The stent cannot be repositioned after the first crown has been deployed. Stent placement in general was an issue with the first Neuroform gen- 


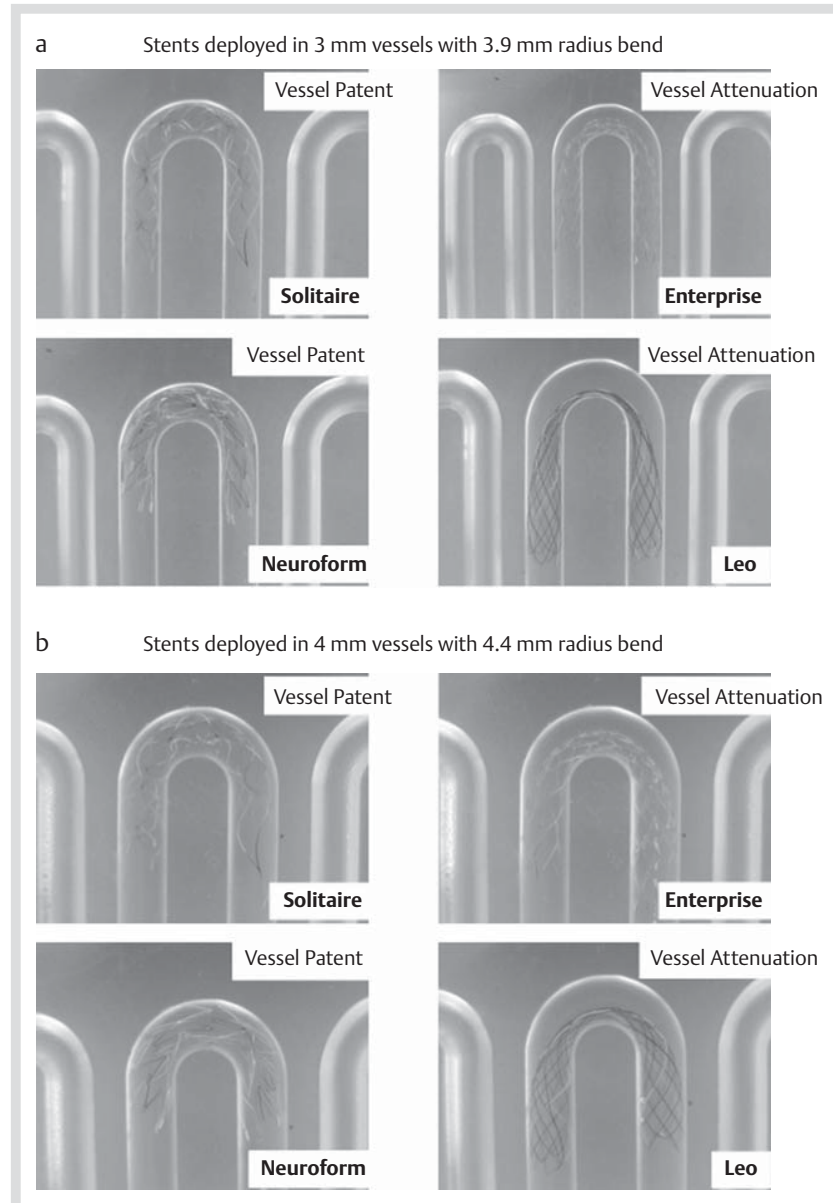

Fig. 5 a: Simulation of a vessel bend $(3.9 \mathrm{~mm})$ in a $3 \mathrm{~mm}$ diameter vessel: Solitaire (upper left panel) and Neuroform3 stent (lower left panel) remain patent, while the Enterprise (upper right panel) is attenuated. b: Simulation of a vessel bend $(4.4 \mathrm{~mm})$ in a $4 \mathrm{~mm}$ diameter vessel: Solitaire (upper left panel) and Neuroform3 stent (lower left panel) remain patent, while the Enterprise (upper right panel) is attenuated.

eration, and was overcome with Neuroform2 and following device variants. The guidewire within the $3 \mathrm{~F}$ stent-catheter running coaxially through the mounted stent, however, remains a potential source of complications due to distal wire injury [14]. The structure of the Neuroform stent is unstable and catheterization of the aneurysm immediately after stent deployment may result in stent displacement. Staged procedures with an interval of $6-8$ weeks between stenting and coiling are therefore recommended for unruptured aneurysms $[15,16]$. Within the first months after stent deployment, complete endothelialization can be expected, unless there is a large gap between stent and the intimal surface [17]. Due to the limited radial force of the Neuroform stent, small vessels with a diameter of less than $2 \mathrm{~mm}$ are well suitable for Neuroform stent placement [18]. The hemodynamic effect of a single Neuroform stent on a bridged aneurysm was found to be insignificant in computational hemodynamic simulations [19]. Telescoping of Neuroform stents instead can sometimes induce flow diversion $[15,20,21]$. In vitro examinations (e.g., ultra-high resolution MicroCT studies) have shown that Neuroform stent deployment may be associated with a variety of adverse phenomena such as focal intercrown separation on the convex side of a vessel curve, penetration of crowns on the concave side, strut vertex misalignment, strut prolapse into the lumen, crown protrusion into large side vessel and aneu-

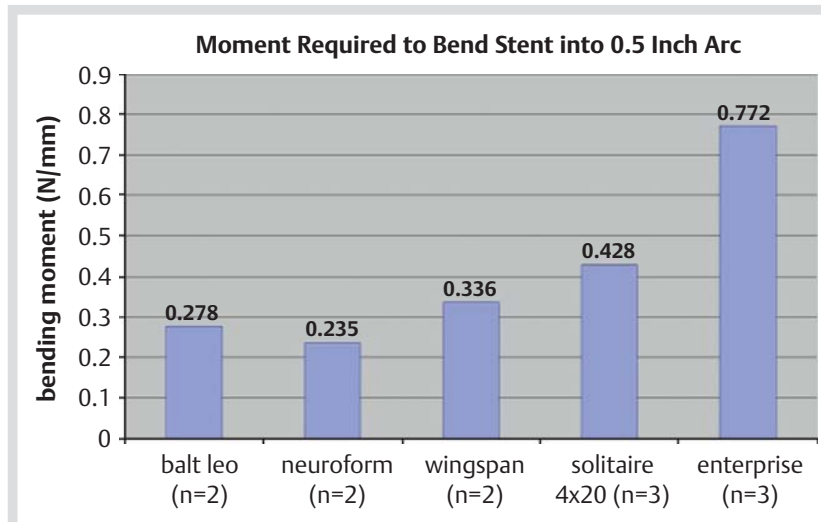

Fig. 6 Bending moment $(\mathrm{N} / \mathrm{mm})$ required to bend the stents into a 0.5 inch arc.

rysm orifice, wall prolapse into the lumen at the cell center, undulations of the vessel wall, strut and marker embedding into the vessel wall and formation of creases at the strut vertices [22-25]. Vessel straightening by Neuroform was described but is of limited importance in clinical practice [25]. All effects related to the open cells of the Neuroform stent are not possible with the competing closed cell stents of this study. Undulations of the vessel walls are sometimes obvious on angiograms after oversized deployment of a Neuroform or Solitaire stent. Fibrocellular in-growth within the stented vessel segment promotes increased durability of coil-occlusion and may be more pronounced in an open-cell design stent [26]. In-stent stenosis due to neointimal hyperplasia occurs in about $5-6 \%$ of patients after Neuroform implantation for aneurysm treatment [27]. Clinically insignificant in-stent stenosis is even more frequent [28]. The rate of in-stent stenosis recurrence after conventional balloon dilatation is high and an accentuation of the intimal hyperplasia adjacent to the stent markers is sometimes evident [29]. In our experience, in-stent stenosis after stent-assisted coiling of aneurysms is generally rare but seems to be increased in patients with underlying vasculitis.

Bifurcation reconstruction can be achieved with both "crossing" and "kissing" using Neuroform stents [30,31].

The Wingspan stent was originally developed for the endovascular treatment of intracranial atherosclerotic stenoses [5]. It is actually a design variant of the Neuroform stent with an optimized delivery system and an increased radial force. Some physicians have reported good results with this stent for aneurysm indications [32]. The increased radial force, which is the main differentiating feature of the Wingspan stent from the Neuroform stent, may add some stability for aneurysm coiling. The high in-stent restenosis rate (e.g., 88\% for supraclinoid stenoses in patients aged 55 years younger) [33] might also be related to the high radial force of the Wingspan stent. The hemodynamic effects of Neuroform and Wingspan are expected to be more or less equivalent but computational fluid dynamics analysis found more influence on intra-aneurysmal blood flow for the Wingspan stent [34].

Solitaire was the first fully retrievable and detachable intracranial stent [6]. The stent is more stable than Neuroform3 and less thrombogenic than Leo(+) in our clinical experience. Due to the large cell size, catheterization of the aneurysm sac after stent deployment is well controllable and may be easier than with the competitors [35]. In our opinion, the Solitaire stent is less prone to microcatheter-induced deformation or displacement, which may happen with Neuroform and Enterprise, respectively. We 

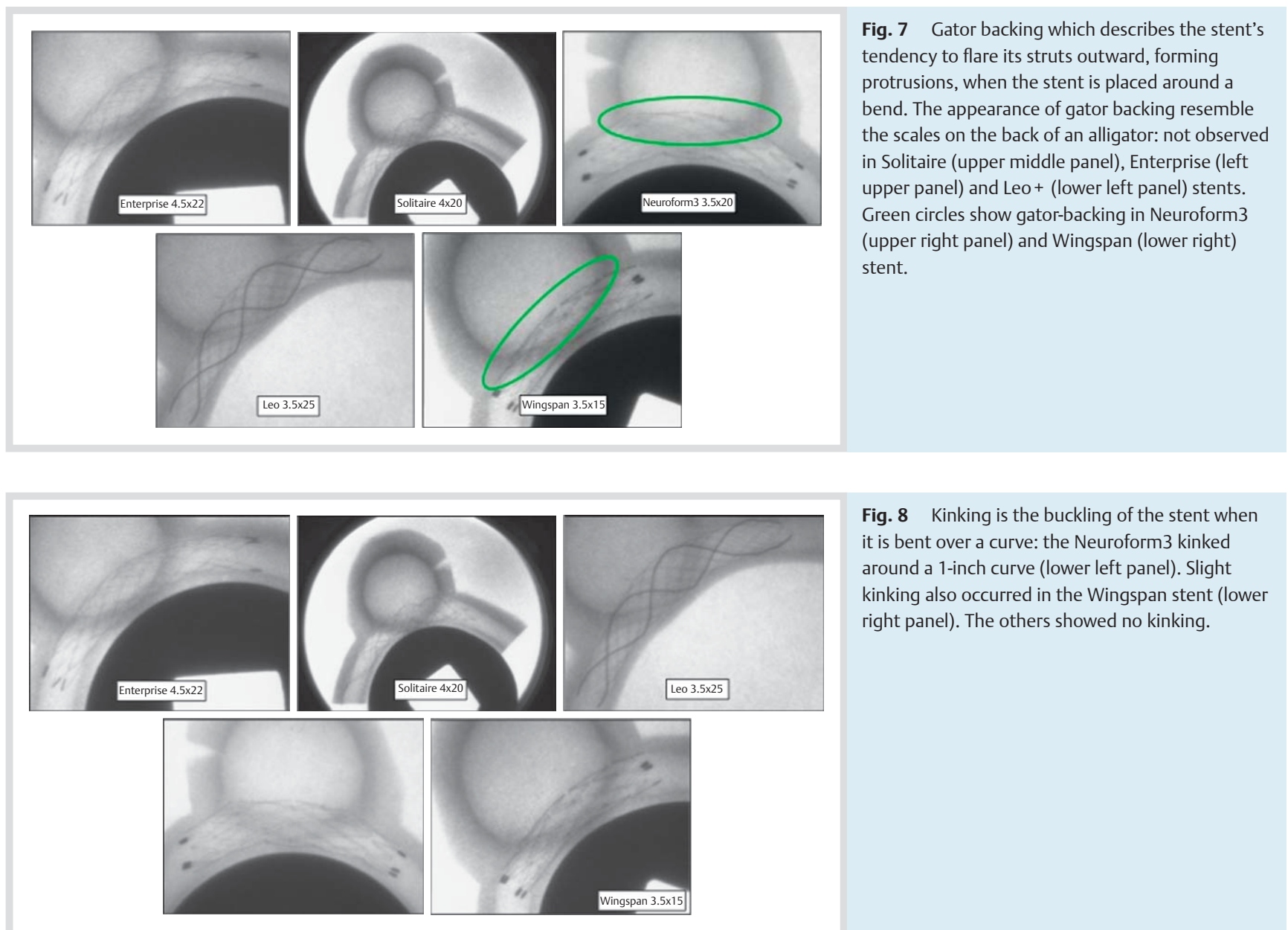

Fig. 8 Kinking is the buckling of the stent when it is bent over a curve: the Neuroform3 kinked around a 1-inch curve (lower left panel). Slight kinking also occurred in the Wingspan stent (lower right panel). The others showed no kinking.

observed that the retrievability of the stent after full deployment allows accurate final positioning as well as temporary stenting similar to balloon remodeling though without blood flow interruption ("stent remodeling"). Controlled detachment can be used to stabilize the stent position during catheterization, coil delivery, or deployment of a second stent. In some clinical situations, there may be an advantage to a stent having a separate guide wire. A central wire running through the lumen of the mounted stent is part of the Neuroform 3 and of the Enterprise stent system but is missing at the Solitaire. Such a wire facilitates recatheterization of a stent once deployed but also carries the risk of distal vessel injury. As observed by other sites, the thrombogenicity of the Solitaire stent is low and allows deployment with heparinization and ASA induced antiaggregation only, without the administration of clopidogrel [35]. This is a major advantage in the treatment of patients with recently ruptured aneurysms. The use of heparinization and ASA-induced antiaggregation only is also valid for Enterprise and Neuroform3 stents. An intrinsic hemodynamic effect of the Solitaire is apparently non-existing, mainly due to the large cell size. Endothelialization can be expected as with every intracranial stent but we are not aware of any case of in-stent stenosis after Solitaireassisted aneurysm coiling. Solitaire is currently not indicated for atherosclerotic stenoses and the in-stent restenosis rate associated with its application in atherosclerotic disease is unknown. Reconstructing vessel bifurcations by crossing stent-in-stent deployment (Y-configuration) is possible with the Solitaire [35]. Leo and Leo + are braided stents, which can be repositioned after partial deployment [36]. Different than laser-cut stents, the
Leo(+)'s cells are closed but not predetermined in size and shape. The cells increase in size at the convexity and decrease in size at the concavity. The Leo stent has a braiding angle of $45^{\circ}$, which is increased to $60^{\circ}$ for the Leo + . In addition the Leo+ comes with flaired proximal and distal ends and with a $30 \%$ increase of radial force [37]. Some authors state a higher radial force for the Leo(+) than the Neuroform3 and the Enterprise stents [38], which is wrong. The original Leo version was known for thromboembolic complications [38]. This issue was overcome with subsequent device modifications, which may be related to the observation that the revised stent $\left(\mathrm{Leo}^{+}\right)$does in vitro show neither midsection flattening nor the inward crimping of the proximal and distal ends [37]. The effective cell size of the Leo(+) stent is influenced by the diameter of the target vessel. Oversizing of the stent (i.e., the stent is unable to fully expand) will result in larger cell sizes. Larger cells are easier accessible for a microcatheter but have less hemodynamic effect on the aneurysm's in- and outflows. Among the stents examined, Leo(+) has in general the most distinct hemodynamic effect, which may purposely be applied for flow diversion [38]. A major drawback of the Leo $(+)$ stent-line is the appendent Vasco microcatheter, which is difficult to navigate in tortuous vessels [37].

The Leo(+) stent does not allow either "crossing" or "kissing" deployment and is therefore not suitable for bifurcation reconstruction.

The Enterprise stent is retractable after partial deployment. Exact placement is mostly easy but penetration of the small stent cells with a microcatheter can be challenging [8,9,39]. The body of the stent itself is almost invisible under fluoroscopy [8]. 


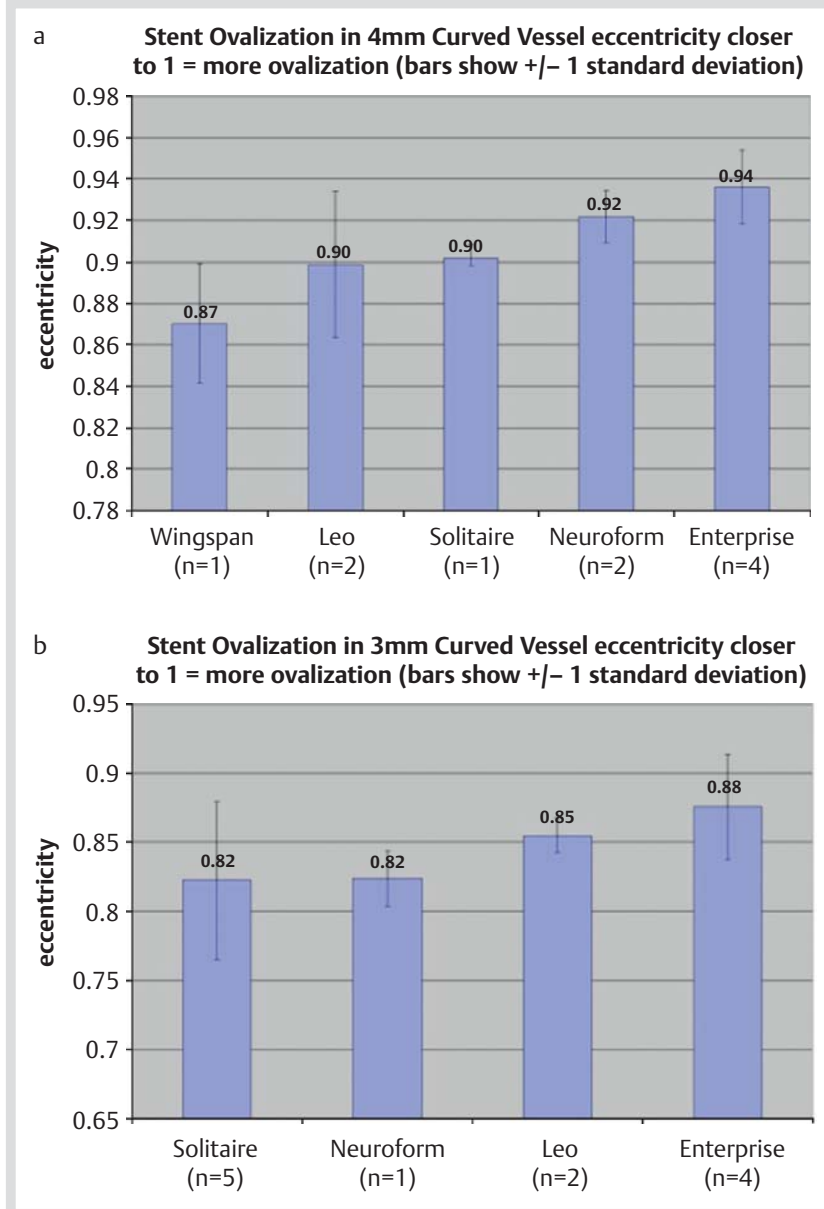

Fig. 9 a: Comparison of the stents' ovalization in a simulated $4 \mathrm{~mm}$ curved vessel. b: Comparison of the stents' ovalization in a simulated $3 \mathrm{~mm}$ curved vessel.

Only proximal and distal tantalum markers allow the identification of the stent position. The ability of the Enterprise stent to retain coils in an aneurysm is excellent. In curves, the cell remains stable but kinking and flattening of the Enterprise body can occur [24]. We used telescoping Enterprise stents several times for attempted flow diversion with poor results, indicating a limited hemodynamic effect. The Enterprise stent is available with a nominal diameter of $4.5 \mathrm{~mm}$, and is indicated for vessel diameters ranging from $2.5 \mathrm{~mm}$ to $4 \mathrm{~mm}$. In-stent stenosis was rarely observed by us after aneurysm treatment. The stent is coated with Parylene $\mathrm{C}$ and has therefore a very smooth surface. Stent displacement may be encountered if coiling is attempted immediately after deployment. Therefore awaiting stent endothelialization or coiling with a "jailed" microcatheter is recommended [9]. An adverse event unique for the Enterprise is secondary proximal migration if a short stent is deployed into vessel segments with large caliber differences [40]. We observed Enterprise in-stent stenosis due to intimal hyperplasia after stenosis treatment with a frequency of about $25 \%$. Focal intimal hyperplasia is sometimes observed at the stent markers. Poor attachment of the end-markers to the vessel surface has been observed for both Neuroform and Enterprise and may induce low wall shear stress as a reason of intimal hyperplasia [25,41]. Similar effects are to be expected for Solitaire.

Both "crossing" and "kissing" deployment for bifurcation reconstruction is possible with the Enterprise stent. Due to the small cell size, "crossing" 2 Enterprise stents, however, can be quite

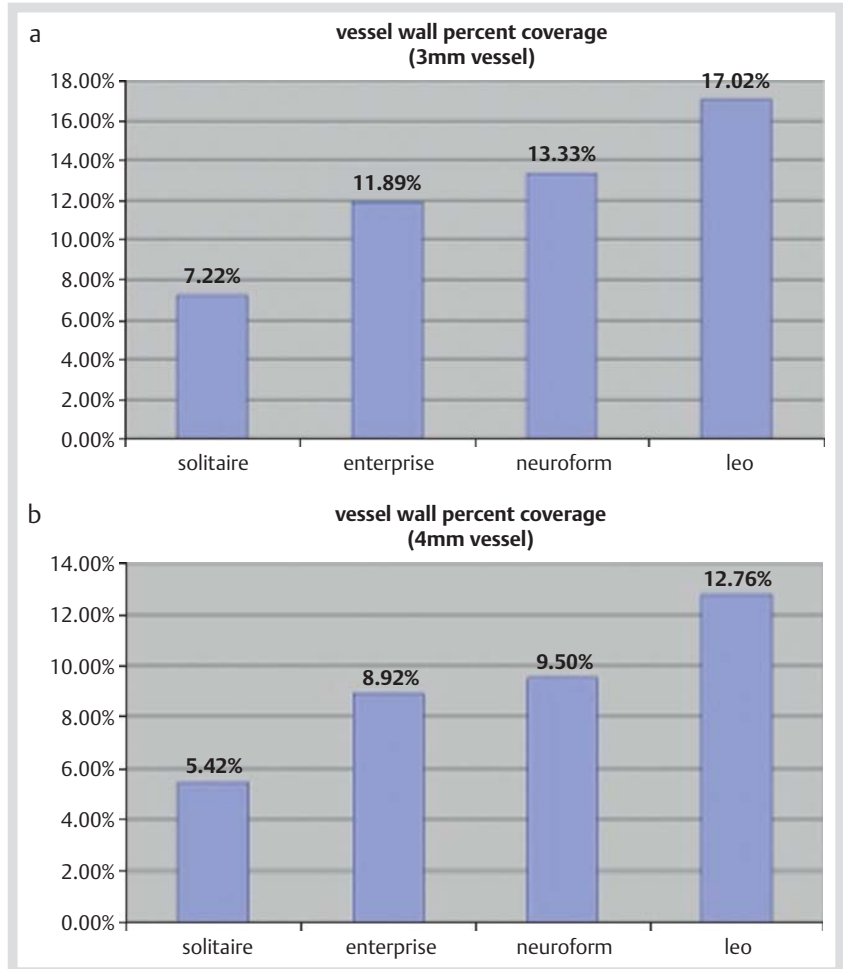

Fig. 10 a and $\mathbf{b}$ : Vessel wall coverage for various stents. The graphs show that the Solitaire stent has the lowest and the Leo + stent has the highest percentage in both $3 \mathrm{~mm}$ simulated vessels and $4 \mathrm{~mm}$ simulated vessels.

difficult. We therefore prefer the combination of a Solitaire with an Enterprise stent for this purpose, deploying the Solitaire stent first into the vessel with the steeper angle. Temporary stent deployment ("stent remodeling" in analogy to balloon remodeling) has successfully been applied with a partially deployed Enterprise stent [42].

There is no comparative study on the safety and efficacy of different self-expanding intracranial aneurysm stents available and in fact such a study would be difficult to justify. In general, Enterprise and Solitaire are certainly more convenient to use than the Neuroform system [39]. Both stents can be deployed through 0.021 " ID microcatheters, which can also be used for coil insertion. The Leo + is a good choice whenever an enhanced hemodynamic effect is required. Some physicians use the Leo+ or Enterprise stent to prepare a target vessel for subsequent flow diverter deployment. Flow diversion by multiple telescoping stents of the same kind has been demonstrated [12,15]. The efficacy of combinations of stents with various designs (e.g., Enterprise or Neuroform with Solitaire) is unknown.

\section{Conclusion}

In 2010 five self-expanding intracranial stents were available. They have basically different physical features and clinical functions. None of these stents is ideal in the sense of universally meeting all possible requirements. Knowledge of the stent features, procedural experience and proper technical skills are mandatory for safe and successful endovascular treatment on the basis of individualized decision making. The medical device industry is asked to address the above shown issues. Systematic variations of existing stent designs and new developments are 
required to further improve the results of intracranial stenting, way beyond aneurysm treatment. Directions of development should include non-thrombogenic stents deployable without anti-aggregation and methods for mid- and long-term temporary stenting (e.g., bioresorbable stents). Aneurysm stents are only the initial ignition for a device family that will improve the treatment of intracranial stenoses, dissections and acute stroke.

Potential conflicts of interest: Özlem Krischek has no potential conflict of interest. Elina Miloslavski participated in clinical trials for Neuroform, Wingspan and Enterprise. Sebastian Fischer has no potential conflict of interest. Sanjay Shrivastava is Director of R \& D for ev3, Irvine, CA, USA. Hans Henkes is co-inventor of the Solitaire stent but has no further financial interest in this device. He participated in clinical trials for Neuroform, Wingspan and Enterprise, was consultant and is proctor to Covidien/ ev3 and is proctor and Medical Board member for Codman Neurovascular.

\section{References}

1 Fernandez Zubillaga A, Guglielmi G, Viñuela F et al. Endovascular occlusion of intracranial aneurysms with electrically detachable coils: correlation of aneurysm neck size and treatment results. AJNR Am J Neuroradiol 1994; 15: 815-820

2 Higashida RT, Smith $W$, Gress $D$ et al. Intravascular stent and endovascular coil placement for a ruptured fusiform aneurysm of the basilar artery. Case report and review of the literature. J Neurosurg 1997; 87: 944-949

3 Solymosi L, Chapot R, Bendszus M. Stent, balloon, or clip? The problem of wide-necked aneurysms. Clin Neuroradiol 2005; 15: 145-160

4 Henkes $H$, Bose A, Felber $S$ et al. Endovascular coil occlusion of intracranial aneurysms assisted by a novel self-expandable nitinol microstent (Neuroform). Intervent Neuroradiol 2002; 8: 107-119

5 Henkes $H$, Miloslavski E, Lowens $S$ et al. Treatment of intracranial atherosclerotic stenoses with balloon dilatation and self-expanding stent deployment (Wingspan). Neuroradiology 2005; 47: 222-228

6 Henkes $H$, Flesser A, Brew S et al. A novel microcatheter-delivered, highlyflexible and fully-retrievable stent, specifically designed for intracranial use Technical note. Intervent Neuroradiol 2003; 9: 391-393

7 Liebig T, Henkes $H$, Reinartz J et al. A novel self-expanding fully retrievable intracranial stent (SOLO): experience in nine procedures of stent-assisted aneurysm coil occlusion. Neuroradiology 2006; 48: 471-478

8 Lubicz B, Francois $O$, Levivier $M$ et al. Preliminary experience with the enterprise stent for endovascular treatment of complex intracranial aneurysms: potential advantages and limiting characteristics. Neurosurgery 2008; 62: 1063-1069

9 Mocco J, Snyder KV, Albuquerque FC et al. Treatment of intracranial aneurysms with the Enterprise stent: a multicenter registry. J Neurosurg 2009; 110: 35-39

10 Kis $B$, Weber $W$, Berlit $P$ et al. Elective treatment of saccular and broadnecked intracranial aneurysms using a closed-cell nitinol stent (Leo). Neurosurgery 2006; 58: 443-450

11 Duerig TW, Tolomeo DE, Wholey M. An overview of superelastic stent design. Minim Invasive Ther Allied Technol 2000; 9: 235-246

12 Colombo A, Stankovic G, Moses JW. Selection of coronary stents. J Am Coll Cardiol 2002; 40: 1021-1033

13 Siewiorek GM, Finol EA, Wholey MH. Clinical significance and technical assessment of stent cell geometry in carotid artery stenting. J Endovasc Ther 2009; 16: 178-188

14 Lylyk P, Ferrario A, Pasbon B et al. Buenos Aires experience with the Neuroform self-expanding stent for the treatment of intracranial aneurysms. J Neurosurg 2005; 102: 235-241

15 Ansari SA, Lassig JP, Nicol E et al. Thrombosis of a fusiform intracranial aneurysm induced by overlapping neuroform stents: case report. Neurosurgery 2007; 60: E950-E951

16 Fiorella D, Albuquerque FC, Masaryk TJ et al. Balloon-in-stent technique for the constructive endovascular treatment of "ultra-wide necked" circumferential aneurysms. Neurosurgery 2005; 57: 1218-1227

17 Lopes D, Sani S. Histological postmortem study of an internal carotid artery aneurysm treated with the Neuroform stent. Neurosurgery 2005; 56: E416

18 Turk AS, Niemann DB, Ahmed A et al. Use of self-expanding stents in distal small cerebral vessels. AJNR Am J Neuroradiol 2007; 28: 533-536
19 Radaelli AG, Augsburger L, Cebral JR et al. Reproducibility of haemodynamical simulations in a subject-specific stented aneurysm model a report on the Virtual Intracranial Stenting Challenge 2007. J Biomech 2008; 41: 2069-2081

20 Cantón G, Levy DI, Lasheras JC et al. Flow changes caused by the sequential placement of stents across the neck of sidewall cerebral aneurysms. J Neurosurg 2005; 103: 891-902

21 Henkes $H$, Reinartz J, Preiss $H$ et al. Endovascular treatment of small intracranial aneurysms: three alternatives to coil occlusion. Minim Invas Neurosurg 2006; 49: 65-69

22 Benndorf G, Claus B, Strother CM et al. Increased cell opening and prolapse of struts of a neuroform stent in curved vasculature: value of angiographic computed tomography: technical case report. Neurosurgery 2006; 58 (4 Suppl 2): ONS-E380

23 Benndorf G, Ionescu M, Valdivia y Alvarado $M$ et al. Anomalous hemodynamic effects of a self-expanding intracranial stent: comparing invitro and ex-vivo models using ultra-high resolution microCT based CFD. J Biomech 2010; 43: 740-748

24 Ebrahimi $N$, Claus B, Lee CY et al. Stent conformity in curved vascular models with simulated aneurysm necks using flat-panel CT: an in vitro study. AJNR Am J Neuroradiol 2007; 28: 823-829

25 Hsu SW, Chaloupka JC, Feekes JA et al. In vitro studies of the Neuroform microstent using transparent human intracranial arteries. AJNR Am J Neuroradiol 2006; 27: 1135-1139

26 Fiorella D, Albuquerque FC, Deshmukh VR et al. Usefulness of the Neuroform stent for the treatment of cerebral aneurysms: results at initial (3-6-mo) follow-up. Neurosurgery 2005; 56: 1191-1201

27 Fiorella $D$, Albuquerque FC, Woo $\mathrm{H}$ et al. Neuroform in-stent stenosis: incidence, natural history, and treatment strategies. Neurosurgery 2006; 59: 34-42

28 Hoit DA, Malek AM. Three-dimensional rotational angiographic detection of in-stent stenosis in wide-necked aneurysms treated with a selfexpanding intracranial stent. Neurosurgery 2005; 57: 1228-1236

29 Fiorella D, Albuquerque FC, Deshmukh VR et al. In-stent stenosis as a delayed complication of neuroform stent-supported coil embolization of an incidental carotid terminus aneurysm. AJNR Am J Neuroradiol 2004; 25: 1764-1767

30 Henkes $H$, Kirsch $M$, Mariushi $W$ et al. Coil treatment of a fusiform upper basilar trunk aneurysm with a combination of "kissing" Neuroform stents, TriSpan-, 3D- and fibered coils, and permanent implantation of the microguidewires. Neuroradiology 2004; 46: 464-468

31 Thorell WE, Chow MM, Woo HH et al. Y-configured dual intracranial stent-assisted coil embolization for the treatment of wide-necked basilar tip aneurysms. Neurosurgery 2005; 56: 1035-1040

32 Yavuz K, Geyik S, Saatci I et al. WingSpan stent system in the endovascular treatment of intracranial aneurysms: clinical experience with midterm follow-up results. J Neurosurg 2008; 109: 445-453

33 Turk AS, Levy EI, Albuquerque FC et al. Influence of patient age and stenosis location on Wingspan in-stent restenosis. AJNR Am J Neuroradiol 2008; 29: 23-27

$34 \mathrm{Kim} \mathrm{M,} \mathrm{Levy} \mathrm{EI,} \mathrm{Meng} \mathrm{H} \mathrm{et} \mathrm{al.} \mathrm{Quantification} \mathrm{of} \mathrm{hemodynamic} \mathrm{changes}$ induced by virtual placement of multiple stents across a wide-necked basilar trunk aneurysm. Neurosurgery 2007; 61: 1305-1312

35 Klisch J, Eger C, Sychra V et al. Stent-assisted coil embolization of posterior circulation aneurysms using Solitaire AB: preliminary experience. Neurosurgery 2009; 65: 258-266

36 Lubicz B, Leclerc X, Levivier M et al. Retractable self-expandable stent for endovascular treatment of wide-necked intracranial aneurysms: preliminary experience. Neurosurgery 2006; 58: 451-457

37 Valdivia y Alvarado M, Ebrahimi N, Benndorf G. Study of conformability of the new Leo plus stent to a curved vascular model using flatpanel detector computed tomography (DynaCT). Neurosurgery 2009; 64: $130-134$

38 Pumar JM, Lete I, Pardo MI et al. Leo stent monotherapy for the endovascular reconstruction of fusiform aneurysms of the middle cerebral artery. AJNR Am J Neuroradiol 2008; 29: 1775-1776

39 Peluso JP, van Rooij WJ, Sluzewski M et al. A new self-expandable nitinol stent for the treatment of wide-neck aneurysms: initial clinical experience. AJNR Am J Neuroradiol 2008; 29: 1405-1408

40 Lavine SD, Meyers PM, Connolly ES et al. Spontaneous delayed proximal migration of enterprise stent after staged treatment of wide-necked basilar aneurysm: technical case report. Neurosurgery 2009; 64: E1012

41 Benndorf G, Ionescu M, YA MV et al. Wall shear stress in intracranial self-expanding stents studied using ultra-high-resolution 3D reconstructions. AJNR Am J Neuroradiol 2009; 30: 479-486

42 Lopes DK, Wells $K$. Stent remodeling technique for coiling of ruptured wide-neck cerebral aneurysms: case report. Neurosurgery 2009; 65: E1007-E1008 